\title{
Performance Studies on Flax Fiber Reinforced Polymer Composites - An Effect on Fiber Orientation
}

\author{
K. Arun Prasath, V. Arumugaprabu, P. Amuthakkannan, V. Manikandan
}

\begin{abstract}
The plant based nature fiber added as a reinforced material for so many structural applications. From this awareness of earlier research in this paper by changing orientation of fiber and the mechanical properties and machining performance of flax fiber evaluated. The preparation of composite polyester resin was used with varying layers of flax fibers. The hand layup technique was adopted to fabricate the composites. The main aim of this research is to find out the effect of the fiber orientation. Different fiber orientations were used like $0^{\circ}, 30^{\circ}, 45^{\circ}, 60^{\circ}$, and 90. Mechanical properties, tensile and flexural strength and abrasive water jet machining also performed to study the kerf angle. It was found that 00 and 900 orientation exhibited the better performance.
\end{abstract}

Keywords : Flax fiber, Fiber orientation, Tensile strength, Ultimate Strength, Machining Performance.

\section{INTRODUCTION}

$\mathrm{N}_{\mathrm{o}}$ owadays natural fiber composites has many applications in automobiles, aerospace etc., Researches approached different strategies to improve the property of the composites. The tensile and flexural properties of the composites were increased by increasing of flax fiber content Clement [1]. The effect of resin flow reduced the void content in the composites achieved good fiber matrix interfacial bonding [2]. Flax fiber has high specific strength and excellent damping property. Flax fiber can improve the mechanical properties of the composites with different orientations [3]. Orientation of the flax fiber and its length has more influence in transferring of load from fiber to matrix, in $0^{\circ}$ fiber orientation ability of composite seen with improved mechanical properties [4]. In hybridization of $0^{\circ}$ oriented flax / glass composite have good tensile and flexural strength then other combinations [5].Some drawbacks existing for glass fibers filled polypropylene composites, machines during processing to resist damages. [6]. Polymers are one of the best materials for degradation in which, with glass, carbon and aramid fibres

Revised Manuscript Received on December 16, 2019.

* Correspondence Author

K.Arun Prasath, Department of Mechanical Engineering, Kalasalingam Academy of Research and Education, Krishnankoil, India Email: arunprasath@klu.ca.in

V.Arumugaprabu*, Department of Mechanical Engineering, Kalasalingam Academy of Research and Education, Krishnankoil, India Email:Email: v.arumugaprabu@klu.ac.in

P.Amuthakkannan, Department of Mechanical Engineering, PSR Engineering College, Sivakasi, India Email: amuthakkannanp@gmail.com

V.Manikandan, Department of Mechanical and Automation, PSN College of Engineering and Technology, Tirunelveli, India Email: vaimanikandan@yahoo.com. continue to increase their market shares with the combined effect with natural fibers [7]. Effects of fibre content in the composite structures will increase the mechanical strength of the composite, especially the use of flax as reinforcement [8],damage criterion (for intra-laminar damage) helps to study about the delamination of the composites with orientation effect. [9]. The introduction of new materials in the market with good eco-friendly, will improves the material stability and performance [10]. The uni directional flax fiber will exhibits less tensile strength, as well as the 45 degree angle so the direction of the fiber will responsible for the property of the composite, the different properties of flax and basalt fibres and their hybrids using a vinyl ester resin can shows good reinforcement in thermosetting composites.[11,12]. The advanced composites, owing to their high specific strength to weight and specific-stiffness-to-weight ratios, they are popular for automotive, marine and construction, because of their attractive properties in terms of weight applications with high performance modulus [13- 15]. The high specific strength and stiffness and excellent damping behavior of flax fibre composites was used in the construction sector. To understanding of the intrinsic non-linear mechanical behavior of flax fibre composites forces the application of larger safety factors to be considered [16]. Natural fibre composites are being utilized increasingly in high-performance, structurally demanding applications, in part because of their material properties and in part because they are a more sustainable choice compared to other engineering materials. [17]. Natural fibres are used for long time as low-cost fillers in the plastic made industry but, nowadays there is replacement with glass fibres in composite structures are more. The involvement of bio-composites and its respective hybrid composites were developed using jute, hemp, and flax natural fibers reinforced with thermoset polymers using various manufacturing techniques for some specific applications[18-20].In this paper, from literatures implicit that by changing orientation of fiber that exhibits some improved property. We planned to study the changes in the property due to the angle of the fiber orientation. The mechanical property of flax fibre polyester composite evaluated by varying layers of flax fibers ( 1 to 10 layers). The main aim of this research is to find out the influence of flax fiber orientation on their mechanical properties. 


\section{MATERIALS AND METHODS}

Unidirectional flax fiber and general purpose polyester resin are used as reinforcement and matrix. Catalyst and accelerator also used for proper curing process. With the help of hand layup techniques the unidirectional flax fiber is placed the mould and polyester resin is prepared with each $2 \%$ of catalyst and accelerator. This mixture stirred well to get homogeneous mixture. Then resin mixture is poured over the fiber and spread the resin manually. Finally hand roller is used to give the pressure over the fiber/resin mixture. Then it is allowed to cure for $24 \mathrm{hrs}$. The fabricated composite is presented in figure 1 .

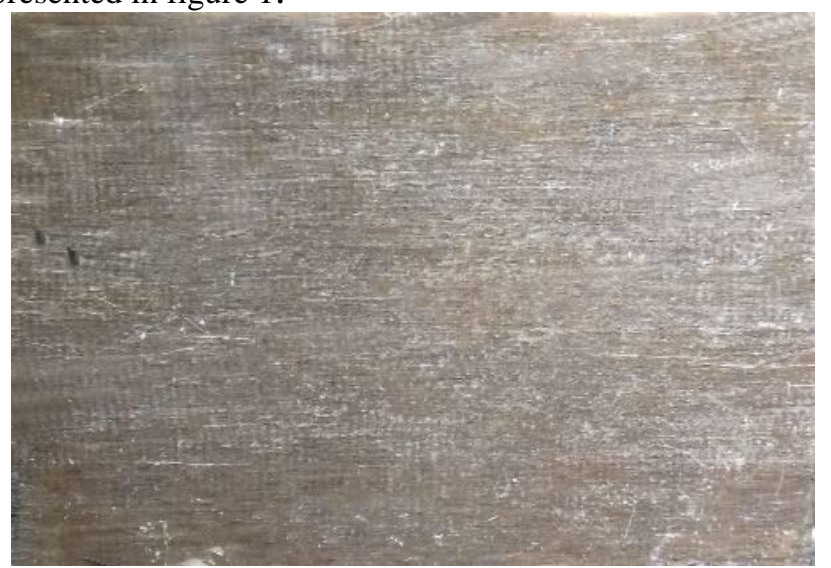

Fig. 1 Flax fiber Polyester Composite

\section{RESULT AND DISCUSSION}

\section{A. Tensile strength}

Fabricated unidirectional flax fiber composites is cut with varying angles like $0^{\circ}, 30^{\circ}, 45^{\circ}, 60^{\circ}, 90^{\circ}$. As per the ASTM D638 standard we prepare our workpiece with the dimension $165 \mathrm{~mm} \times 13 \mathrm{~mm} \times 3 \mathrm{~mm}$. Tensile tests were performed according to ASTM D638 standard, using an Instron universal Tester.

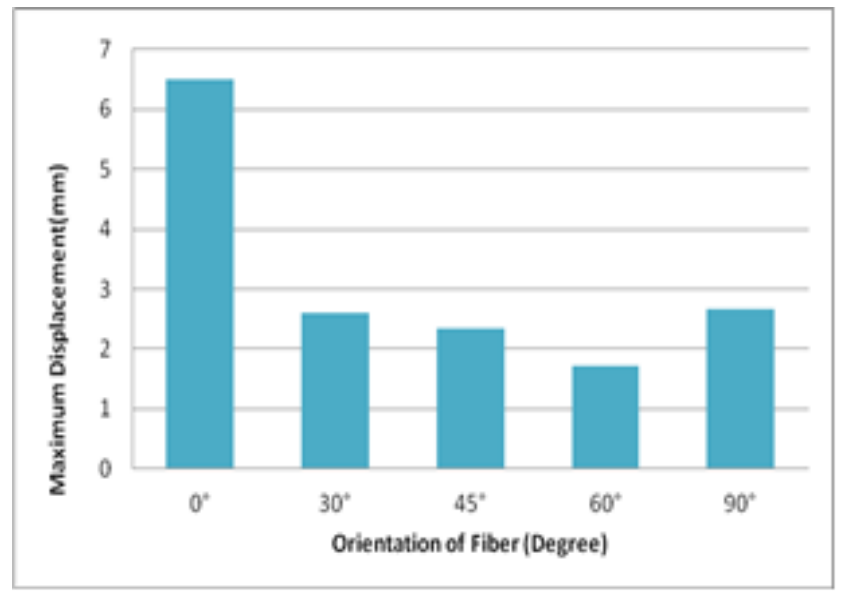

Fig. 2 Maximum Displacement of the flax fiber composites

Maximum displacement of flax fiber is presented in Figure 2, Maximum Displacement of flax fiber is observed in smallest degree of orientation. That is $0^{\circ}$ is obtain overall maximum displacement of Flax fiber composite which presented in Figure 2.

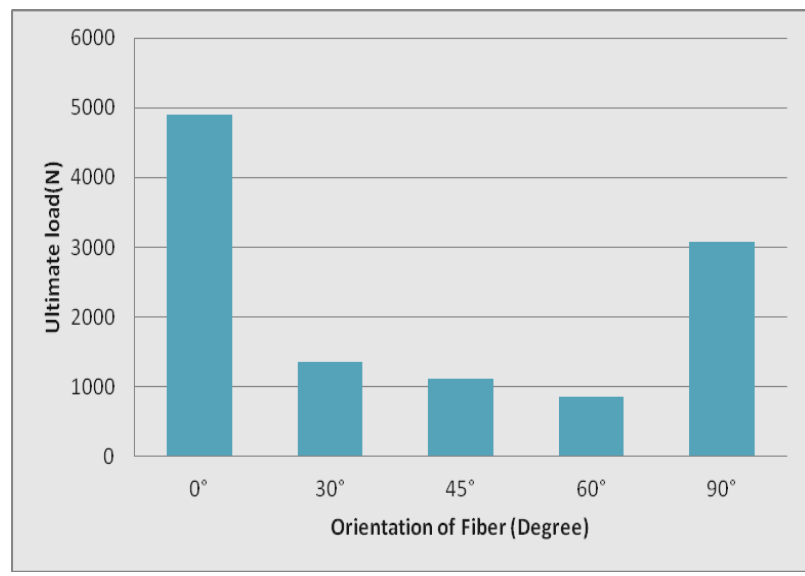

Fig.3 Ultimate load of flax fiber composite

It is observed that the increasing of flax fiber orientation increases of Ultimate load of the composites. $0^{\circ}$ is obtained Ultimate Load of Flax fiber composite. Graphical diagram of ultimate load is shown in figure 3 .

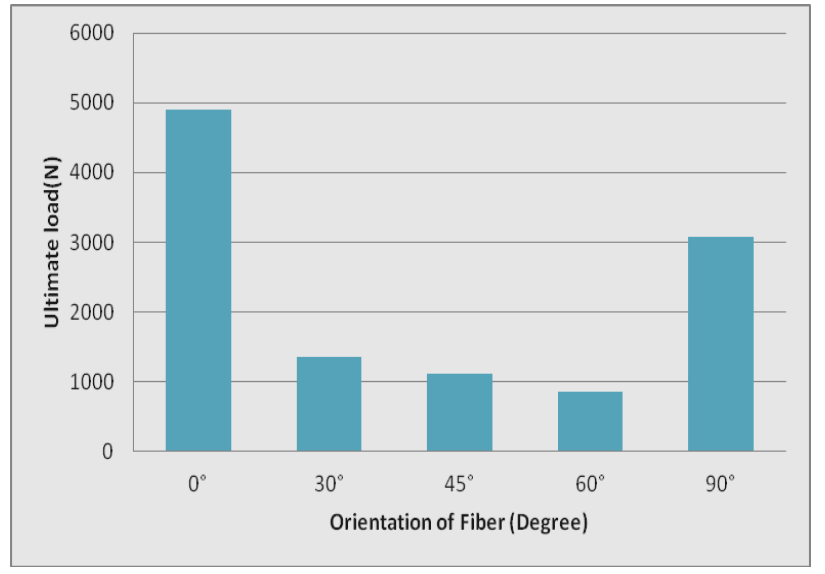

Fig.4 Ultimate load of flax fiber composite

Ultimate Load of the composite is presented in table. It is observed that the increasing of flax fiber orientation increases of Ultimate load of the composites. $0^{\circ}$ is obtained Ultimate Load of Flax fiber composite. Graphical diagram of ultimate load is shown in figure 4.

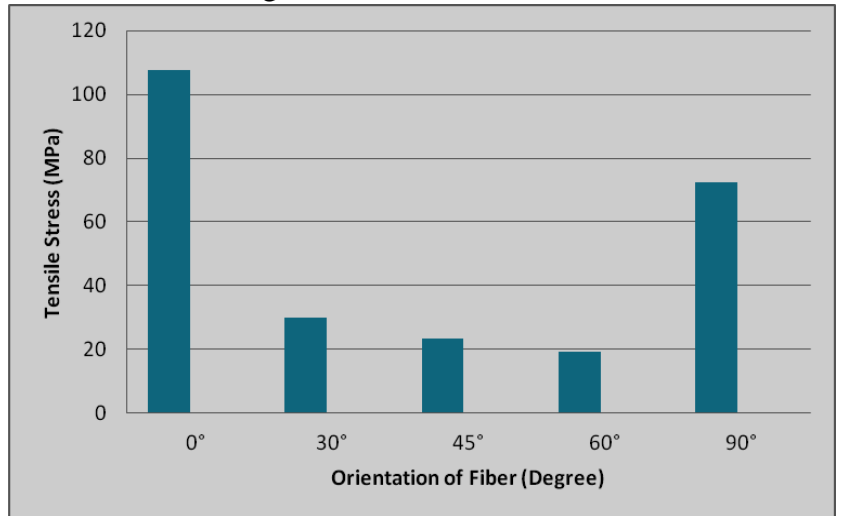

Fig.5 Tensile stress of composites

Tensile strength of the composite is presented in the table. It is observed that the increasing of flax fiber orientation increases of tensile length of the composites.

Published By:

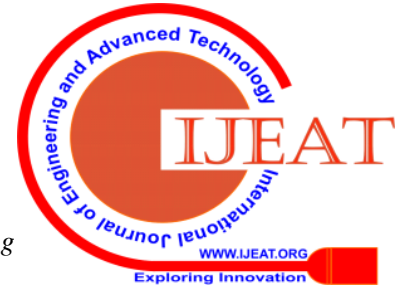


Orientation of the flax fiber highly influencing the tensile strength of the composites. Due to orientation of the fiber which carries the tensile load. When angle increased, the contribution of the fiber in load carrying was increased. Graphical diagram of tensile strength is shown in figure 5.

\section{B. Flexural strength}

As per the ASTM D790 standard we prepare our work piece with the dimension $127 \mathrm{mmx} 13 \mathrm{mmx} 3 \mathrm{~mm}$. Flexural tests were performed according to ASTM D790 standard, using again an Instron universal tester.

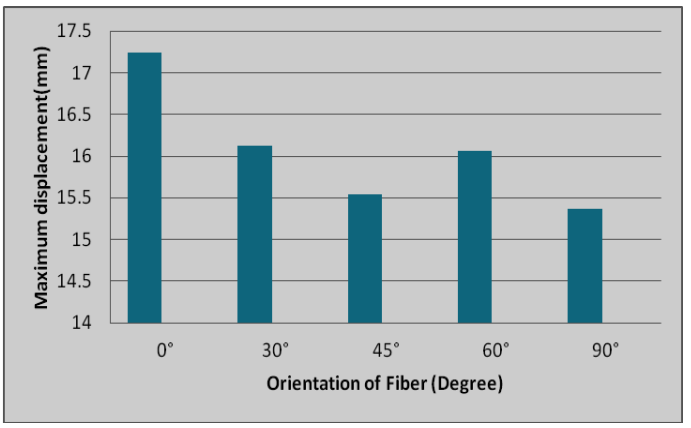

Fig.6 Maximum Displacement during bending test

Maximum displacement of flax fiber is presented in table Maximum displacement on flexural test is observed in 0 orientation of composite. Maximum displacement of th composites was obtained at $0^{\circ}$. Maximum displacement $\mathrm{i}$ decreasing in $90^{\circ}$ orientation of composite.

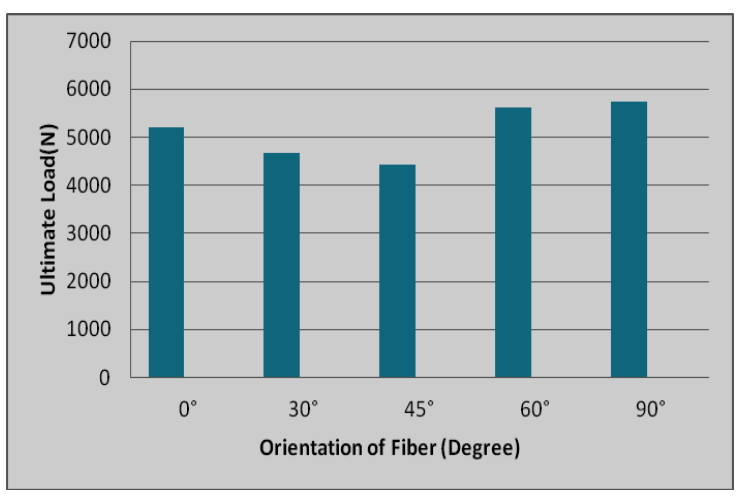

Fig.7 Ultimate load during flexural test Ultimate Load of the composite is presented in the figure 7. Ultimate load is observed in $90^{\circ}$ orientation of composite in flexural test. It is highly increasing in $90^{\circ}$ orientation of composite. Lower value of ultimate load is obtained in $45^{\circ}$ orientation.

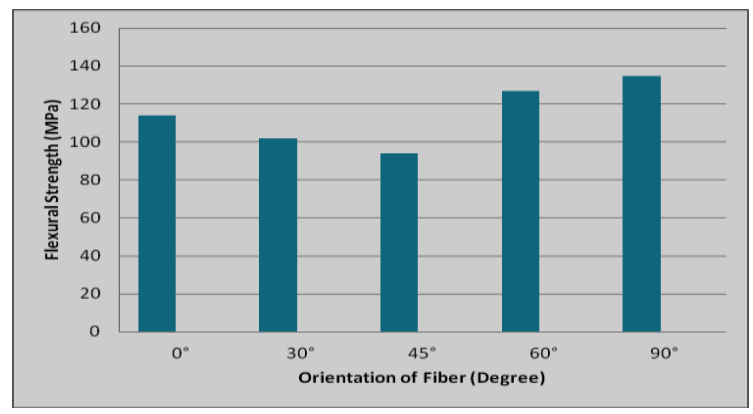

Fig.8 Orientation of Fiber vs Flexural Strength
Figure 8 presented the flexural strength of the composites. It was observed that from $0^{\circ}$ orientations there are increases in flexural strength till $45^{\circ}$, and then it starts increased for $60^{\circ}$ and $90^{\circ}$ orientations. $90^{\circ}$ orientation of flax fiber composites exhibited better flexural strength. Bending load also influence the orientation of the composites.

\section{Machining performance}

Abrasive Water jet machining is performed in the composites to mmeasure kerf angle. The top and bottom surface width of the machined composites measured with help of microscope. By using this formula to measure the kerf angle in degree $\left(^{\circ}\right.$ ).

$$
\text { Kerfangle }=\operatorname{Tan}^{-1}\left[\left(\mathrm{~W}_{\mathrm{T}^{-}}-\mathrm{W}_{\mathrm{B}}\right) / 2 \mathrm{~T}\right]---(1)
$$

Where, $\mathrm{W}_{\mathrm{T}}-$ Top width

$\mathrm{W}_{\mathrm{B}}-$ Bottom width, $\mathrm{T}-$ Thickness of the specimen. Table-1:Kerf results and calculation

\begin{tabular}{|c|c|c|c|c|c|c|}
\hline S.No & Pressure & SOD & $\begin{array}{c}\text { Travel } \\
\text { speed }\end{array}$ & $\begin{array}{c}\text { Top } \\
\text { surface } \\
(\mathrm{mm})\end{array}$ & $\begin{array}{c}\text { Bottom } \\
\text { surface } \\
(\mathrm{mm})\end{array}$ & $\begin{array}{c}\text { Kerf } \\
\text { angle } \\
\left({ }^{\circ}\right)\end{array}$ \\
\hline 1. & 200 & 1 & 10 & 1.276 & 1.074 & 1.651 \\
\hline 2. & 200 & 2 & 20 & 1.413 & 1.059 & 2.904 \\
\hline 3. & 200 & 3 & 30 & 1.591 & 1.116 & 3.893 \\
\hline 4. & 230 & 1 & 20 & 1.382 & 1.032 & 2.871 \\
\hline 5. & 230 & 2 & 30 & 1.405 & 1.185 & 1.807 \\
\hline 6. & 230 & 3 & 10 & 1.782 & 1.364 & 3.432 \\
\hline 7. & 260 & 1 & 30 & 1.432 & 1.146 & 2.341 \\
\hline 8. & 260 & 2 & 10 & 1.645 & 1.245 & 3.279 \\
\hline 9. & 260 & 3 & 20 & 1.699 & 1.28 & 3.435 \\
\hline
\end{tabular}

From table 1, the machining operation, it was observed that the standoff distance of $3 \mathrm{~mm}$, and travel speed of $30 \mathrm{~mm} / \mathrm{min}$ and pressure $200 \mathrm{MPa}$ showed the highest kerf angle. Specimen L1 showed the lowest kerf angle compared to the other machining parameters tested. It is cleared evident that at lower value machining parameters the kerf angle also minimum.

\section{CONCLUSION}

Unidirectional Flax fiber reinforced polymer composite was manufactured with fiber orientation of $0^{\circ}, 30^{\circ}, 45^{\circ}, 60^{\circ}, 90^{\circ}$ using hand layup techniques successfully. The mechanical properties likes' tensile and flexural strength of the composite was measured in universal tensile machine. The following conclusions were draw. Maximum Displacement of flax fiber is observed in smallest degree of orientation, which means $0^{\circ}$ is obtain overall maximum displacement of Flax fiber composite.

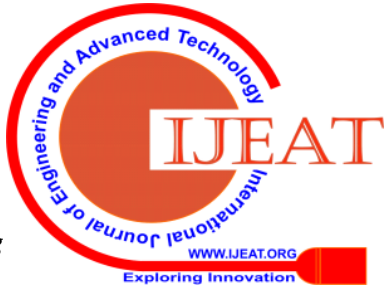


Ultimate load was observed that the increasing of flax fiber orientation increases of ultimate load of the composites. The maximum tensile was observed at $0^{\circ}$ flax fiber orientation as 107.749 $\mathrm{MPa}$ and Maximum displacement on flexural test was observed in $0^{\circ}$ orientation of composite. Ultimate load was observed in $90^{\circ}$ orientation of composite during flexural test. It is highly increasing in $90^{\circ}$ orientation of composite. Maximum flexural strength was observed at $90^{\circ}$ flax fiber orientation as $34.78 \mathrm{MPa}$. Flax fiber orientation of $0^{\circ}$ and $90^{\circ}$ showed better and there composites can be applied to the places where there properties essential one.

\section{REFERENCES}

[1] Audibert, Clement, Anne-Sophie Andreani, Eric Laine, and Jean-Claude Grandidier. Mechanical characterization and damage mechanism of a new flax-Kevlar hybrid/epoxy composite. J Compos Mater 195 (2018) p.p.126-135.

[2] Khanlou, Hossein Mohammad, Peter Woodfield, John Summerscales, Gaston Francucci, Benjamin King, Sepehr Talebian, Javad Foroughi, and Wayne Hall. Estimation of mechanical property degradation of poly (lactic acid) and flax fibre reinforced poly (lactic acid) bio-composites during thermal processing. J Dyn Syst-T ASME 116 (2018) p.p.367-372.

[3] Fragassa, Cristiano, Ana Pavlovic, and Carlo Santulli. Mechanical and impact characterisation of flax and basalt fibre vinylester composites and their hybrids. Composites Part B Engineering 137 (2018)p.p. 247-259.

[4] Fu, Sirui, Bowen Yu, Wei Tang, Mao Fan, Feng Chen, and Qiang Fu. Mechanical properties of polypropylene composites reinforced by hydrolyzed and micro fibrillated Kevlar fibers. J Compos Mater 163 (2018) p.p.141-150.

[5] Lau, Kin-tak, Pui-yan Hung, Min-Hao Zhu, and David Hui. Properties of natural fibre composites for structural engineering applications. Composites Part B Engineering 136 (2018) p.p.222-233.

[6] Hu, Jianxing, Sha Yin, T. X. Yu, and Jun Xu. Dynamic compressive behavior of woven flax-epoxy-laminated composites. International Journal of Impact Engineering 117 (2018) p.p.63-74.

[7] Almansour, F. A., H. N. Dhakal, and Zhong Yi Zhang. Investigation into Mode II interlaminar fracture toughness characteristics of flax/basalt reinforced vinyl ester hybrid composites. Compos Sci Tech 154 (2018) p.p.117-127.

[8] Habibi, Mohamed, Luc Laperriere, and Hojjat Mahi Hassanabadi. Influence of low-velocity impact on residual tensile properties of nonwoven flax/epoxy composite. J Compos Mater 186 (2018) ) p.p.175-182.

[9] Perremans, Dieter, Ignace Verpoest, Christine Dupont-Gillain, and A. W. Van Vuure. Investigation of the tensile behavior of treated flax fibre bio-composites at ambient humidity. Compos Sci Tech 159 (2018) p.p.119-126.

[10] Park, Gilsu, and Hyunbum Park. Structural design and test of automobile bonnet with natural flax composite through impact damage analysis. Compos Sci Tech 184 (2018): ) p.p. 800-806.

[11] Sahoo, Sushanta K., Smita Mohanty, and Sanjay K. Nayak. Mechanical, Thermal, and Interfacial Characterization of Randomly Oriented Short Sisal Fibers Reinforced Epoxy Composite Modified with Epoxidized Soybean Oil. Journal of natural fibers 14, no. 3 (2017) ) p.p.357-367.

[12] Koh, Rachel and Bo Madsen. Strength failure criteria analysis for a flax fibre reinforced composite. Mechanics of Materials 124 (2018) p.p.26-32.

[13] Papanicolaou, G. C., D. A. Chalkias, and A. F. Koutsomitopoulou. Thermal shock cycling effect on the mechanical behavior of epoxy matrix-woven flax fabric composites. In AIP Conference Proceedings, Publishing 2018,p.p.298-306.

[14] Wang, Wenjie, Xuejie Zhang, Nawawi Chouw, Zhongxian Li, and Yanchao Shi. Strain rate effect on the dynamic tensile behaviour of flax fibre reinforced polymer. Compos Sci Tech 200 (2018) ) p.p.135-143.

[15] Huang, Kede, Le Quan Ngoc Tran, Umeyr Kureemun, Wern Sze Teo, and Heow Pueh Lee. Vibroacoustic behavior and noise control of flax fiber-reinforced polypropylene composites. Journal of Natural Fibers (2018) ) p.p. 1-15.
[16] Alamri, Hatem, and It Meng Low.Mechanical properties and water absorption behaviour of recycled cellulose fibre reinforced epoxy composites. Polymer testing (2012) ) p.p.620-628.

[17] Yu, Hang, and Chuwei Zhou. Sandwich diffusion model for moisture absorption of flax/glass fiber reinforced hybrid composite. J Compos Mater 188 (2018) ) p.p. 1-6

[18] Sepe, R., F. Bollino, L. Boccarusso, and F. Caputo. Influence of chemical treatments on mechanical properties of hemp fiber reinforced composites. Composites Part B Engineering 133 (2018) ) p.p. 210-217.

[19] Riccio, A., A. Raimondo, S. Saputo, A. Sellitto, M. Battaglia, and G. Petrone. A numerical study on the impact behaviour of natural fibres made honeycomb cores. J Compos Mater 202 (2018) ) p.p. 909-916.

[20] Chaudhary, Vijay, Pramendra Kumar Bajpai, and Sachin Maheshwari. Studies on mechanical and morphological characterization of developed jute/hemp/flax reinforced hybrid composites for structural applications. Journal of natural fibers 151 (2018) ) p.p. 80-97.

\section{AUTHORS PROFILE}

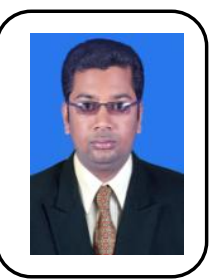

K. ArunPrasath, working as an Assistant Professor in the Department of Mechanical Engineering ,Kalasalingam Academy of Research and Education, Krishnankoil. He has research experience in the field of cellular manufacturing and published some good works in reputed journals. And also his research extend to composite materials for low velocity applications

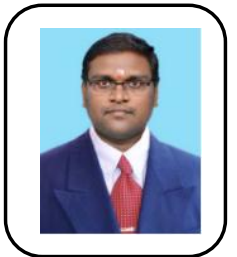

Dr.V.Arumugaprabu, working as an Associate Professor in the Department of Mechanical Engineering ,Kalasalingam Academy of Research and Education, Krishnankoil. He has expertise in the area of red mud filled composite materials and industrial safety. And also he published so many papers in reputed journals.

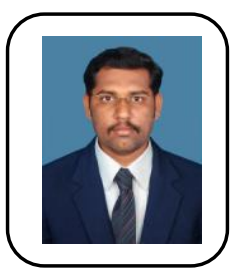

Dr.P.Amuthakkannan, working as an Department of Mechanical Engineering, PSR Engineering College, Sivakasi. His area of interest in basalt fiber polyester composites and mathematical modeling. He published so many papers and reviewer for reputed journals.

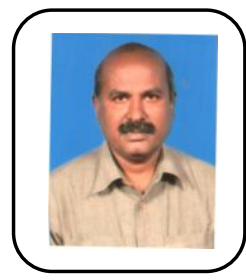

Dr.V.Manikandan, working as Principal, PSN College of Engineering and Technology, Tirunelveli. His area was industrial waste recycling of composite materials and natural fiber composites. And also he published so many papers in reputed journals. 